\title{
A POLÍTICA DE ASSISTÊNCIA ESTUDANTIL E SEU IMPACTO NA PERMANÊNCIA DOS ESTUDANTES
}

\author{
STUDENT ASSISTANCE POLICY AND ITS IMPACT ON KEEPING THE \\ STUDENTS
}

\author{
BEATRIZ SIMONAIO BIRELLI FALCO ${ }^{1}$ \\ ISABEL CRISTINA DAS CHAGAS OLIVEIRA²
}

\begin{abstract}
RESUMO: O presente artigo tem como objetivo apresentar uma reflexão sobre as políticas de democratização de ensino e sua atuação na permanência e êxito dos estudantes dos cursos técnicos de nível Médio, do Instituto Federal de Educação, Ciência e Tecnologia de São Paulo Câmpus Capivari (IFSP-CPV). Em questões metodológicas, será apresentada uma abordagem quantitativa, uma vez que avalia o alcance da Política de Assistência Estudantil em relação ao número de alunos atendidos e o impacto em suas vidas. O levantamento de dados mostra que, no período de 2015 a 2019, dos alunos beneficiados nos cursos técnicos integrados ou concomitantes/subsequentes ao Ensino Médio, o índice de evasão foi de 14\%, ou seja, $86 \%$ dos contemplados não desistiram do curso. Os resultados obtidos mostram que a Política de Assistência Estudantil é um programa decisivo para a permanência dos estudantes, garantindo necessidades básicas e auxiliando nos estudos e desenvolvimento de suas potencialidades.
\end{abstract}

Palavras-chaves: Democratização de ensino. Política de Assistência Estudantil. Permanência. Exxito. Instituto Federal de Educação, Ciência e Tecnologia de São Paulo.

ABSTRACT: The purpose of this article is to present a reflection on the democratization policies of teaching and their performance in the permanence and success of students in the technical courses of secondary level, from the Federal Institute of Education, Science and Technology of São Paulo - Câmpus Capivari (IFSP- CPV). For a methodological statement, a quantitative approach will be presented, as it assesses the scope of the Student Assistance Program in relation to the number of students and the impact on their lives. Data shows that in the period from 2015 to 2019, the students from the integrated technical courses or concurrent / subsequent to high school the abandonment rate is of only $14 \%$, being that $86 \%$ of the students served did not withdraw the course. Results show that the Student Assistance Policy is a decisive program for the permanence of students, guaranteeing and support students with basic needs and and development of their potential.

Keywords: Democratization of education. Student Assistance Policy. Permanence. Success. Federal Institute of Education, Science and Technology of São Paulo.

\footnotetext{
${ }^{1}$ Mestre em Literatura e Vida Social pela UNESP. Graduada em Letras pela Universidade Estadual Paulista e Pedagogia pela Universidade Nove de Julho. Técnica em Assuntos Educacionais do Instituto Federal de Educação, Ciência e Tecnologia de São Paulo, Câmpus Capivari. E-mail:beatriz.falco@ifsp.edu.br

${ }^{2}$ Mestre em Educação pela UNISAL, com Pós-Graduação pela UNIFAL em Teorias e Práticas na Educação e Graduação em Pedagogia pela Universidade Presidente Antônio Carlos. Pedagoga do Instituto Federal de Educação, Ciência e Tecnologia de São Paulo, Câmpus Capivari. E-mail: isabel.chagas@ifsp.edu.br
} 


\section{CONSIDERAÇÕES INICIAIS}

Este trabalho é resultante das reflexões, das vivências e do campo de atuação das autoras do texto, integrantes da Coordenadoria Sociopedagógica, do Instituto Federal de Educação, Ciência e Tecnologia de São Paulo - Capivari (IFSP-CPV), no que se refere à Política de Assistência Estudantil do Câmpus.

A pesquisa compõe-se de dois eixos principais: em um primeiro momento, pretende-se refletir sobre a história da Educação brasileira e a importância das políticas de democratização de ensino para garantir o acesso, a permanência e o êxito dos estudantes de baixa renda e pertencentes a minorias étnicas, público este tão excluído de todo o processo educacional brasileiro. Para isso, foi feito um breve resumo histórico sobre o início da Educação formal no Brasil e as principais leis que marcaram a trajetória do ensino em nosso país.

Em um segundo momento, visa-se analisar a importância e o alcance de uma das políticas de ações afirmativas existentes, o Programa Nacional de Assistência Estudantil PNAES, no IFSP-CPV. Baseado em dados retirados do Sistema Unificado da Administração Pública $^{3}$, de editais de resultado final do programa estudado e, também, de documentos institucionais sobre o tema, foi feito um levantamento da quantidade de alunos dos cursos técnicos de nível Médio beneficiados com algum tipo de auxílio estudantil no período de 2015 a 2019, bem como uma análise de sua realidade socioeconômica. Posteriormente, verificamos, entre os alunos beneficiados, aqueles que cancelaram a sua matrícula ou realizaram transferência para uma instituição diversa.

Dessa forma, foi possível realizar um diagnóstico do Programa no Câmpus de atuação das escritoras, além de realizar um registro da história e desenvolvimento da Política de Assistência Estudantil na Instituição.

Espera-se, portanto, que os resultados obtidos do estudo possam contribuir com o fortalecimento e luta a favor das políticas afirmativas, principalmente nas universidades e instituições públicas, gratuitas e de qualidade, promovendo, assim, a inclusão social por meio da educação, na tentativa de corrigir e compensar distorções histórica ou atuais.

\footnotetext{
${ }^{3}$ O SUAP (Sistema Unificado de Administração Pública) é um sistema para informações acadêmicas e de solicitação de documentos por parte da comunidade acadêmica.
} 


\section{UM OLHAR SOBRE A HISTÓRIA DA EDUCAÇÃO FORMAL BRASILEIRA}

Foi com a chegada dos jesuítas, no período Colonial, que se iniciou, no Brasil, a Educação formal. A Companhia de Jesus, trazida de Portugal, tinha como principal objetivo catequizar os índios e desenvolver um trabalho de conformação disciplinar, moral e intelectual à situação de colonização. Para Mattos (1958), já era o esboço de um sistema educacional, que se consolidaria em períodos subsequentes.

Em 1564, com a destinação de dez por cento dos impostos arrecadados da colônia brasileira para a manutenção da educação jesuíta, diversos colégios foram construídos e um plano de estudo, Ratio Studiorum, foi criado com a finalidade de ser usado por todo jesuíta, em qualquer lugar do mundo, proposto aos filhos dos colonos.

Durante os dois primeiros séculos de colonização, foram, então, os jesuítas os responsáveis pela educação, que, aos poucos, foi se voltando para a elite e, consequentemente, tornou-se um instrumento de ascensão social. Com isso, os primeiros objetivos educacionais foram alterados e a educação dos índios foi colocada em segundo lugar: "o plano legal (catequizar e instruir os índios) e o plano real se distanciaram. Os instruídos eram descendentes dos colonizadores. Os indígenas foram apenas catequizados” (RIBEIRO, 1986, p.29).

Essa ação pedagógica jesuíta marca o começo de uma educação elitizada e excludente no país. Com a expulsão dos jesuítas e a Reforma Pombalina, o Estado passa a assumir, pela primeira vez, a responsabilidade pela educação. Mas o que se vê, nos séculos seguintes, é que o direito à educação ainda permanecia restrito a uma minoria da sociedade.

Somente com a vinda da Família Real ao Brasil, em 1808, que as primeiras escolas de nível superior foram criadas; porém, com o intuito de atender às necessidades da Corte:

[...] ao invés de procurar montar um sistema nacional de ensino, integrado em todos os seus graus e modalidades, as autoridades preocuparam-se mais em criar algumas escolas superiores e em regulamentar as vias de acesso a seus cursos, especialmente através do curso secundário e dos exames de ingresso aos estudos de nível superior (PILETTI, 2010, p. 41).

Vê-se, portanto, que a história da Educação brasileira é marcada, desde seu início, pelas desigualdades. Na época da Independência, por exemplo, estima-se que 40\% dos habitantes não tinham acesso à educação. (CURY, 2008, p. 210)

Nos últimos 30 anos, diversas reformas e modificações foram promovidas na educação brasileira. Entre elas, pode-se citar a garantia do direito de educação para todos, presente na Constituição Federal de 1988, que estabelece em seu artigo 205: "A educação, direito de todos 
e dever do Estado e da família, será promovida e incentivada com a colaboração da sociedade, visando ao pleno desenvolvimento da pessoa, seu preparo para o exercício da cidadania e sua qualificação para o trabalho" (BRASIL, 1988).

Em seu artigo seguinte, artigo 206, inciso I, apresenta a necessidade de garantia de igualdade de condições de acesso e permanência na escola. Já a Lei de Diretrizes e Bases da Educação Nacional (Lei n. 9.394/1996), explicita a necessidade de promoção da educação no que tange ao dever do Estado. Em seu artigo $4^{\circ}$, inciso VIII, estabelece o: "atendimento ao educando, em todas as etapas da educação básica, por meio de programas suplementares de material didático-escolar, transporte, alimentação e assistência à saúde".

Além das leis citadas, outros projetos e legislações foram criados com a finalidade de democratizar o acesso ao ensino em suas diferentes etapas. Porém, para que esse direito se efetive, não basta estar garantido por lei, é preciso políticas públicas que promovam e assegurem o acesso, a permanência e o êxito desses estudantes.

Dentre as discussões sobre o conceito de políticas de ações afirmativas, Neves e Lima afirmam que, nos últimos anos, elas têm sido voltadas para a diminuição de diferenças socioeconômicas entre algumas categorias sociais. Nesse sentido, compreender que estão pautadas na ideia de que,

[...] para garantir a igualdade de direitos, é necessária a ação do Estado no sentido de oferecer condições especiais àqueles que, por razões de ordem social, econômica, cultural ou política, estão originalmente em situação desfavorável de competição com outros membros da sociedade. (NEVES e LIMA, 2010, p. 57).

Como visto anteriormente, a história da Educação brasileira é caracterizada pela dependência, exploração, desrespeito às diferenças, sendo, em sua grande maioria, uma educação domesticadora e elitista. Por isso, também é preciso discutir a conceituação das políticas de ações afirmativas pelo viés dos direitos humanos:

As ações afirmativas, como políticas compensatórias adotadas para aliviar e remediar as condições resultantes de um passado de discriminação, cumprem uma finalidade pública decisiva para o projeto democrático: assegurar a diversidade e a pluralidade social. Constituem medidas concretas que viabilizam o direito à igualdade, com a crença de que a igualdade deve moldar-se no respeito à diferença e à diversidade. Por meio delas, transita-se da igualdade formal para a igualdade material e substantiva. (PIOVESAN, 2005, p.49)

Diante desses princípios fundamentais da política de ações afirmativas, na tentativa de corrigir e compensar distorções históricas ou atuais, o Plano de Desenvolvimento Institucional 
do Instituto Federal de Educação, Ciência e Tecnologia de São Paulo destaca que as Políticas de Ações Afirmativas da instituição caracterizam-se por “(...) ações de inclusão nas atividades de Ensino, Pesquisa e Extensão, visando a promoção do respeito à diversidade socioeconômica, cultural, étnico-racial, sexual e de gênero, do público-alvo da educação especial e para a defesa e promoção dos direitos humanos" (PDI, 2019-2023, p.239).

Dessa forma, o documento propõe medidas especiais para o acesso, a permanência e o êxito dos estudantes em todos os cursos que oferece, sendo essas ações prioritárias para pretos, pardos, indígenas, quilombolas, público alvo da educação especial, travestis, transgêneros e oriundos de escolas públicas.

Dentre as políticas públicas de ações afirmativas que favorecem a garantia do direito ao acesso e permanência dos discentes, pode-se citar, também, a Lei n ${ }^{\circ} 12.711$, de 29 de agosto de 2012, mais conhecida como política de cotas. Essa lei é um marco na história da educação brasileira por favorecer o ingresso nas universidades federais e nas instituições federais de ensino técnico de nível médio, reservando, por curso e turno, uma porcentagem de suas vagas para estudantes de baixa renda e pertencentes a minorias étnicas.

No entanto, garantir o ingresso e não pensar na permanência não teria tanta eficácia, uma vez que as políticas de acesso não são suficientes para garantir a permanência e êxito desses estudantes. Sendo assim, é preciso considerar a inclusão e a exclusão, o acesso, a permanência e a evasão de forma conjunta para que a porta de entrada nas instituições não seja uma porta giratória, como descrito por Ezcurra (2011): é o fenômeno da inclusão excludente, alguns alunos entram nas instituições e saem, antes de se formarem.

Por esse motivo, dentro das políticas de ações afirmativas, encontramos o Programa Nacional de Assistência Estudantil - PNAES. Instituído pela Portaria Normativa n 39, de 12 de dezembro de 2007, do Ministério da Educação, o PNAES em seu Art. $3^{\circ}$, propõe que:

$\int 1^{\circ}$ As ações de assistência estudantil devem considerar a necessidade de viabilizar a igualdade de oportunidades, contribuir para a melhoria do desempenho acadêmico e agir, preventivamente, nas situações de repetência e evasão decorrentes da insuficiência de condições financeiras.

Mas somente em 2010 foi institucionalizado pelo Ministério da Educação e hoje é regido pelo Decreto $\mathrm{n}^{\circ}$ 7.234, de 19 de julho de 2010, que dispõe sobre o Programa Nacional de Assistência Estudantil - PNAES. Diante de sua proposta, apresenta como objetivos: a democratização das condições de permanência dos jovens na educação superior pública federal; a tentativa de minimizar os efeitos das desigualdades sociais e regionais na permanência 
e conclusão da educação superior; a redução das taxas de retenção e evasão; e a contribuição para a promoção da inclusão social por meio da educação.

Embora seja proposto para os cursos de nível superior nas instituições públicas federais de educação, o Programa atende também outros níveis de ensino dos institutos federais, devido a suas características próprias, com destaque para os cursos de nível médio:

O PAE 4 no IFSP, em consonância com o PNAES, tem os seguintes objetivos: democratizar as condições de permanência dos estudantes regularmente matriculados no IFSP, minimizar os efeitos das desigualdades sociais e regionais na permanência e conclusão, em todos os níveis de escolaridade, pelos estudantes, reduzir as taxas de evasão e contribuir para a promoção da inclusão social pela educação. (PDI, 20192023, p.260)

A aprovação do PNAES pode ser considerada um marco no que se refere à assistência estudantil no Brasil. Por meio de uma lei, o governo federal se responsabiliza com o repasse financeiro às instituições federais de ensino superior e, também, de ensino médio, materializando, assim, a assistência estudantil como uma política pública.

\section{O IFSP E AS AÇÕES DA POLÍTICA DE ASSISTÊNCIA ESTUdANTIL NO CÂMPUS CAPIVARI}

Os Institutos Federais de Educação, Ciência e Tecnologia foram criados no âmbito do Ministério da Educação em 2008. Porém, sua história data de mais de cem anos, já que a maior parte das instituições que formam hoje a Rede Federal de Educação Profissional, Científica e Tecnológica são originárias das Escolas de Aprendizes Artífices, de 1909.

Baseados em um conceito de educação profissional e tecnológica de qualidade, os Institutos Federais possuem câmpus espalhados por todo o território brasileiro, além de várias unidades avançadas. Desde sua implantação, há uma divisão na porcentagem das suas ofertas: no artigo $8^{\circ}$, da Lei $n^{\circ} 11.892$, de 29 de dezembro de 2008, há a garantia do mínimo de $50 \%$ (cinquenta por cento) das suas vagas para atender aos cursos de nível médio; mínimo de $20 \%$ (vinte por cento) de suas vagas para os cursos de licenciatura, bem como programas especiais de formação pedagógica, com vistas na formação de professores; e os outros 30\% (trinta por cento) destinados a cursos superiores de graduação, pós-graduação, dentre outros.

Para Pacheco,

\footnotetext{
${ }^{4}$ Política de Assistência Estudantil
} 
Os Institutos Federais de Educação Ciência e Tecnologia são a síntese daquilo que de melhor a Rede Federal construiu ao longo de sua história e das políticas de educação profissional e tecnológica do governo federal. São caracterizados pela ousadia e inovação, necessárias a uma política e um conceito que buscam antecipar aqui e agora as bases de uma escola contemporânea do futuro e comprometida com uma sociedade radicalmente democrática e socialmente justa. (2010, p.11)

Na construção dessa história, a cidade de Capivari foi escolhida para a implantação de mais um de seus câmpus: em 2010, o Câmpus Avançado Capivari foi criado, vinculado ao Câmpus Salto, em ato oficial realizado em Brasília, conduzido pelo então Presidente da República Luiz Inácio Lula da Silva.

No mês de maio de 2013, o Instituto Federal de Capivari foi promovido de Câmpus Avançado para Câmpus Pleno e hoje oferece cursos técnicos integrados e concomitantes ao Ensino Médio, cursos de nível superior, além de curso de pós-graduação, de extensão e de aperfeiçoamento interno.

A estrutura multicampi dos institutos federais e a definição do território de abrangência faz com que tenham a função de assumir “(...) o compromisso de intervenção em suas respectivas regiões, identificando problemas e criando soluções técnicas e tecnológicas para o desenvolvimento sustentável com inclusão social” (Ibidem, p. 12).

Como dito anteriormente, o presente trabalho tem como objetivo analisar a realidade dos estudantes do Câmpus Capivari e avaliar o quanto a Política de Assistência Estudantil do IFSP-CPV tem de impacto no que se refere à permanência e êxito dos estudantes em vulnerabilidade social.

Para isso, será feito um recorte temporal (2015 a 2019), uma vez que foi a partir de 2015 que o Câmpus começou a ofertar seus cursos técnicos integrados de forma independente, ou seja, sem parcerias com a Secretaria Estadual de Educação.

Atualmente, a instituição possui aproximadamente 754 alunos regularmente matriculados. Para a realização da análise e compreensão de nosso contexto escolar, utilizamos informações provenientes do questionário "Caracterização Socioeconômica" referentes ao primeiro semestre de 2020, presente na plataforma SUAP. Ao todo, 508 alunos responderam ao questionário, sendo, em sua maioria, alunos inscritos no Programa de Assistência Estudantil. ${ }^{5}$

\footnotetext{
${ }^{5}$ Vale ressaltar que, nesse diagnóstico, não há alunos do curso Técnico em Administração Integrado ao Ensino Médio - PROEJA, uma vez que de acordo com a Resolução No 42/2015, de 02 de junho de 2015, em seu artigo 34, "todos os estudantes regularmente matriculados e com frequência igual ou superior a $75 \%$ nos cursos desenvolvidos no âmbito do PROEJA poderão receber o auxílio financeiro legal”. Sendo assim, tais estudantes realizam a Caracterização Socioeconômica de forma diferente dos demais alunos.
} 
No que diz respeito à renda dos estudantes, observa-se que $88,3 \%$ possuem renda per capita que configura o público prioritário do PNAES. Importante destacar que, para ser contemplado pela Assistência estudantil, o estudante precisa passar por um processo de análise em que um dos critérios é possuir renda per capta de no máximo 1 e 1/2 salário mínimo.

Figura 1- Renda per capita familiar dos alunos matriculados no Câmpus Capivari

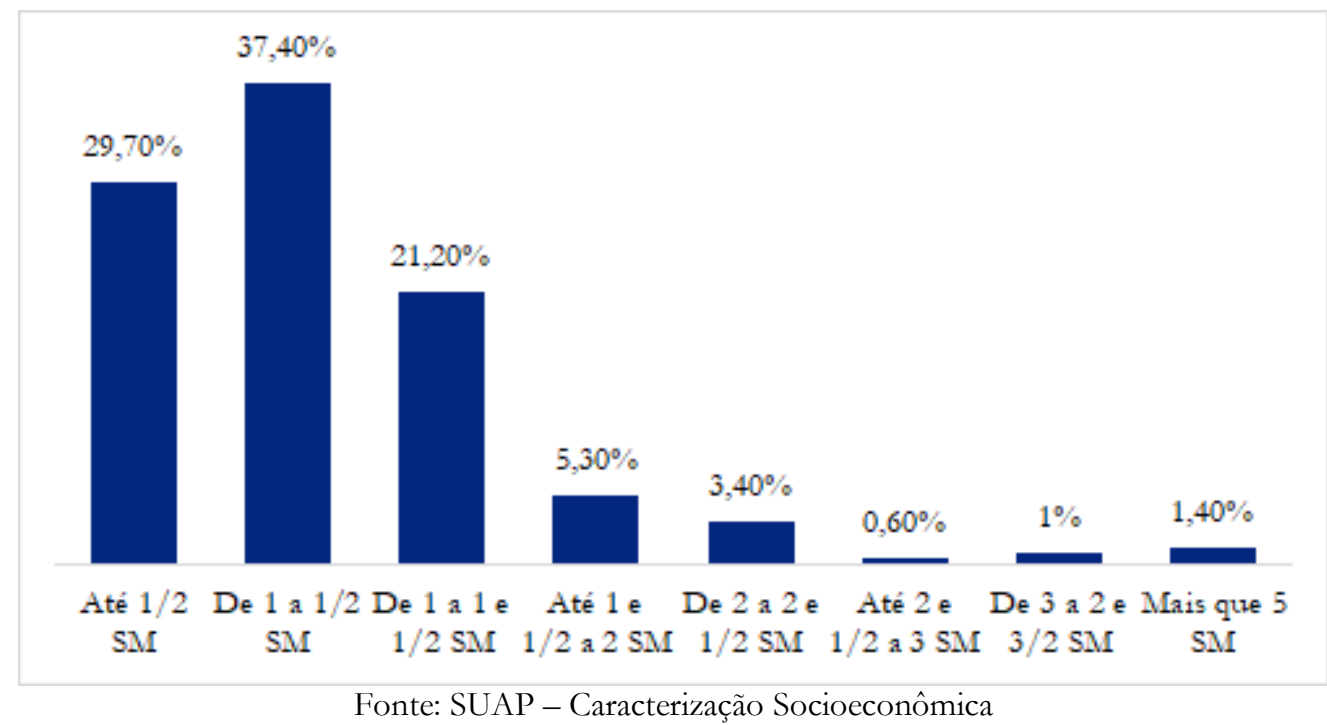

Quanto à origem escolar, a maioria dos estudantes são advindos da rede pública de ensino. Em relação ao ensino fundamental, 85\% concluíram somente em escola pública. Já em relação ao ensino médio, o percentual de estudantes é de $83,9 \%$, sem considerar os não informados.

Figura 2 - Tipo de Escola cursada no Ensino Fundamental dos alunos matriculados no Câmpus Capivari

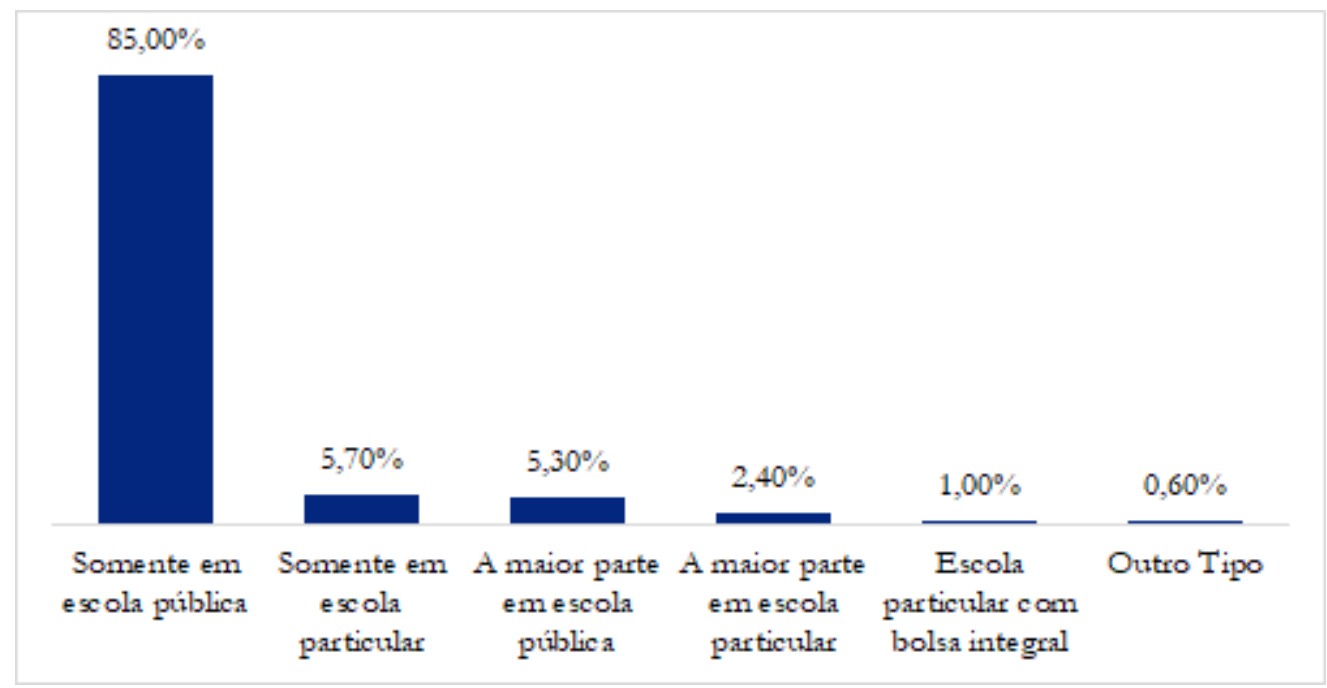

Fonte: SUAP - Caracterização Socioeconômica 
Figura 3 - Tipo de Escola cursada no Ensino Médio dos alunos matriculados no Câmpus Capivari

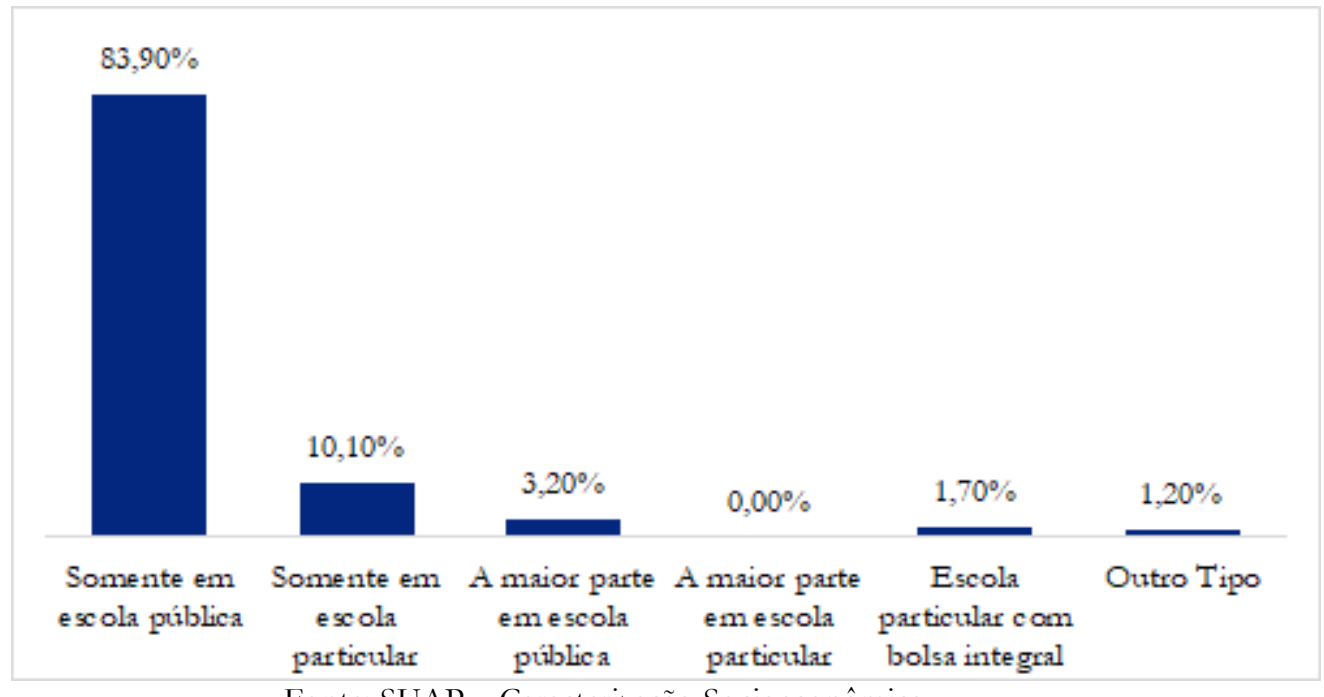

Fonte: SUAP - Caracterização Socioeconômica

Pode-se citar, também, alguns dados retirados do site "Cidades", do Instituto Brasileiro de Geografia e Estatística (IBGE, 2017), sobre as características sociodemográficas da cidade de Capivari em comparação a outros municípios. No âmbito “trabalho e rendimento”, em 2017, o salário médio mensal era de 2,4 salários mínimos. A proporção de pessoas ocupadas em relação à população total era de $29,8 \%$.

Diante do perfil socioeconômico dos discentes e das características sociodemográficas da cidade em que se insere o Câmpus, compreende-se que a Política de Assistência Estudantil tem como objetivo ampliar as condições de acesso, permanência e êxito dos estudantes que integram os cursos oferecidos pela instituição, de forma a contribuir, também, para a redução dos índices de evasão escolar. Para Pacheco,

\footnotetext{
Na necessária articulação com outras políticas sociais, os Institutos Federais devem buscar a constituição de Observatórios de Políticas Públicas, tornando-as objetos de sua intervenção através das ações de ensino, pesquisa e extensão articulada com as forças sociais da região (2010. p.12).
}

Como já mencionado, o Programa de Auxílio Permanência é destinado aos estudantes em situação de vulnerabilidade social, prioritariamente oriundos da rede pública de educação básica e/ou com renda familiar per capita de até um salário mínimo e meio (Decreto $\mathrm{n}^{\circ}$ 7.234/2010). Mas há, também, o Programa de Ações Universais, proposto a toda comunidade discente, independentemente da situação socioeconômica, e o Programa de apoio ao estudante 
PROEJA, em que todos os estudantes com matrícula e frequência regulares nessa modalidade têm direito ao recebimento do auxílio.

Vê-se que os programas transitam em todas as áreas dos direitos humanos, compreendendo ações que têm em vista desde as necessidades mais básicas do corpo discente, tais como alimentação e transporte, até o acesso a meios pedagógicos/científicos/culturais que possam contribuir para a formação dos estudantes.

Para analisarmos a relevância dos auxílios da Assistência Estudantil na vida dos estudantes do IFSP-CPV, também realizamos uma análise levando em consideração os diversos editais do Câmpus. Fizeram parte desta pesquisa alunos dos seguintes cursos técnicos de nível médio ofertados pelo Câmpus Capivari: Técnico em Química Integrado ao Ensino Médio, Técnico em Informática Integrado ao Ensino Médio e Técnico em Química Concomitante/ Subsequente.

Não foram objeto de estudo, nesse momento, alunos do Programa de apoio ao estudante PROEJA, já que todos são contemplados, e os estudantes que receberam auxílios das Ações Universais, pois, embora seja compreendida sua importância para o processo educativo dos estudantes, estes foram pagos esporadicamente e somente diante de disponibilidade orçamentária, algo que tem sido um fator dificultador de promoção no Câmpus, visto que os recursos disponibilizados não são suficientes para suprir todas as necessidades básicas do público atendido.

A partir do levantamento de dados e análise feita, foi possível identificar questões significativas sobre a Assistência Estudantil que mostram sua importância na permanência dos estudantes dos cursos analisados. Um desses destaques está em sua base quantitativa, ou seja, seu alcance em relação ao número de alunos atendidos.

Considerando os editais de processos seletivos, há, anualmente, o ingresso de 120 alunos nos cursos técnicos analisados nesta pesquisa do Câmpus Capivari desde 2015. Sendo assim, no período de 2015 a 2019, temos um total de 600 ingressantes nesses cursos. Desse total, foi identificado que 307 receberam auxílio da Assistência Estudantil pelo menos em um dos anos. Esse número de alunos atendidos corresponde a 51,16\%, pouco mais da metade dos estudantes dos cursos analisados.

Diante dessas informações, pensando no impacto da Assistência Estudantil na vida escolar dos alunos, é importante trazer outros dados sobre a permanência. Nesta perspectiva, foi identificado que, do total dos cancelamentos e transferências de matrícula dos estudantes dos cursos analisados, dos 100\% dos discentes que evadiram, $72 \%$ não recebiam assistência e 
$28 \%$ recebiam. Considerando apenas os alunos que recebem a assistência, o índice de evasão é $14 \%$, ou seja, $86 \%$ dos alunos beneficiados não desistiram do curso.

A maioria desses estudantes foi contemplado com auxílio transporte e auxílio alimentação. Embora alguns deles também tenham recebido auxílio saúde e auxílio creche, os números não são significantes se comparados com o pagamento dos auxílios citados.

Dentre os motivos que dificultam a permanência dos estudantes, ou seja, que favorecem a evasão, podem ser identificados fatores internos e/ou externos. Entendemos como fatores internos aqueles que estão relacionados ao processo de ensino e aprendizagem; à estrutura física adequada, instalações e equipamentos; relação professor-aluno e outros que estão sobre a governabilidade da instituição. Mas existem fatores externos, dos mais diversos possíveis, que nem sempre estão dentro das possibilidades de resolução do Câmpus, como problemas familiares, incompatibilidade com o horário do trabalho e dificuldades financeiras.

Fazendo um resgate histórico, é possível identificar que, no decorrer dos anos, os valores disponibilizados para uso na Assistência Estudantil de 2015 a 2019 não foram suficientes para atender a toda a demanda. Nos anos anteriores a 2015, todos que solicitavam algum auxílio da Assistência Estudantil eram contemplados, já que os recursos recebidos eram compatíveis com o número de alunos do câmpus.

No entanto, a partir de 2015, com a chegada de um número maior de estudantes, percebeu-se que o recurso não era mais suficiente para atender a todas as solicitações, sendo que, muitas vezes, alunos em baixa vulnerabilidade e que também teriam direito ao auxílio não recebiam por falta de disponibilidade orçamentária.

Figura 4 - Disponibilidade orçamentária anual X Alunos matriculados no IFSP - Câmpus Capivari 


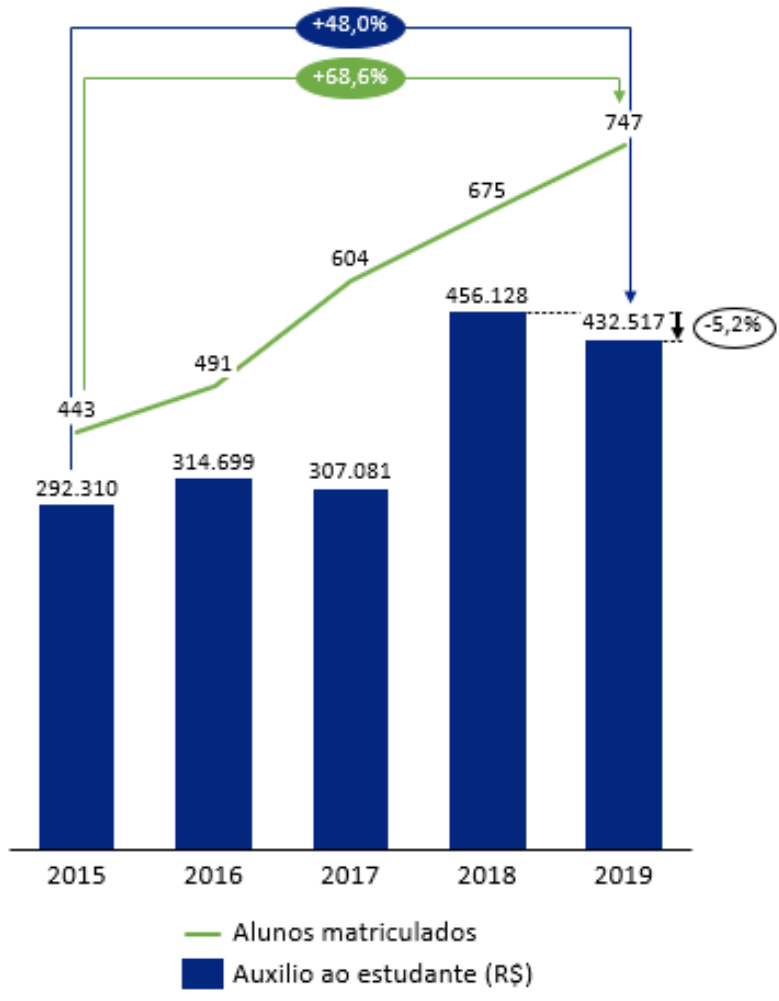

Fonte: Tesouro Gerencial e SUAP

Tabela 1 - Cálculo do valor da Assistência Estudantil por aluno

\begin{tabular}{|l|c|c|c|c|c|}
\hline \multicolumn{5}{|c|}{ Relatório Política de Assistência Estudantil } \\
\hline & ANO 2015 & ANO 2016 & ANO 2017 & ANO 2018 & ANO 2019 \\
\hline $\begin{array}{c}\text { Cálculo que cada aluno receberia } \\
\text { anualmente, se todos fossem } \\
\text { contemplados pela PAE }\end{array}$ & $\mathrm{R} \$ 659,84$ & $\mathrm{R} \$ 640,93$ & $\mathrm{R} \$ 508,41$ & $\mathrm{R} \$ 675,74$ & $\mathrm{R} \$ 579,01$ \\
\hline
\end{tabular}

Fonte: Tesouro Gerencial e SUAP

No período analisado, o orçamento anual apresentou um aumento de $48 \%$, enquanto o quantitativo de alunos matriculados teve um aumento de 68, 6\%. Ou seja, o recurso não acompanhou a evolução do Câmpus em relação ao quantitativo de discentes, fazendo com que a equipe da Coordenadoria Sociopedagógica, responsável pelo planejamento e execução da Política de Assistência Estudantil, tivesse que priorizar algumas ações em detrimento de outras.

Como mostram as figuras 1, 2 e 3, a maior parte dos alunos matriculados nos diversos cursos do câmpus se enquadra no perfil socioeconômico prioritário do PNAES. Entretanto, os 
dados apresentados na figura 4 e na tabela 1 indicam o quanto não há, ainda, a garantia da manutenção de valores que possam atender a todas as necessidades básicas dos estudantes.

Percebe-se que, embora em 2015 o recurso disponível se comparado ao número de alunos seja maior, nos dois anos seguintes, esses valores tiveram uma queda considerável. Em 2018, dentre os anos avaliados, o Câmpus recebeu o maior valor destinado à Assistência Estudantil. Com isso, foi possível realizar pagamentos para estudantes em baixa vulnerabilidade e também realizar ações universais. Contudo, em 2019, houve uma queda no orçamento em relação ao ano anterior, apesar do aumento significativo no número de alunos matriculados.

Nesse sentido, mesmo compreendendo a importância da Assistência Estudantil para a permanência dos estudantes e reconhecendo a sua relevância no processo de formação dos alunos em vulnerabilidade social, não há, até o presente momento, uma política que consiga contemplar a todos que dela necessitam.

\section{CONSIDERAÇÕES FINAIS}

Diante dessa proposta e das análises realizadas, entende-se que esse programa pode ser decisivo para a permanência do estudante dentro da instituição de ensino, pois ela garante que sejam atendidas necessidades básicas como saúde, alimentação, transporte, moradia, esporte, cultura, lazer, inclusão digital, apoio em material didático, participação em eventos científicos, entre outras. A Política de Assistência Estudantil do IFSP se configura enquanto uma possibilidade para que os estudantes em vulnerabilidade social possam estudar e desenvolver suas potencialidades, podendo concluir com êxito seus estudos.

Dessa maneira, compreende-se a permanência como sendo um fator que depende não somente da força de vontade do estudante em realizar o curso, mas também de outros motivos que podem ser definitivos. Com isso, a Política de Assistência Estudantil é elemento fundamental para favorecer a permanência dos estudantes do IFSP-CPV, pois é capaz de transformar algumas condições externas e internas, fatores estes decisivos para a permanência ou evasão dos estudantes.

Pode-se concluir, portanto, que a " $\mathrm{AE}^{6}$ deve ser discutida sob a perspectiva de múltiplas funções, social, pedagógico, psicológica, econômica e podendo ser expandida para outros aspectos de acordo com a realidade local da instituição". (DUARTE, 2019, p. 75). Sendo assim, entende-se que a Assistência Estudantil se configura enquanto uma possibilidade para que os

\footnotetext{
${ }^{6}$ Assistência Estudantil
} 
estudantes em vulnerabilidade social possam continuar a vivenciar o espaço escolar diante da necessidade de garantir condições objetivas em sua realidade social.

\section{REFERÊNCIAS}

BRASIL. Constituição da República Federativa do Brasil de 1988. Disponível em: <http://www.planalto.gov.br/ccivil 03/constituicao/constituicao.htm> Acesso em: 04 set. 2020 .

DECRETO No 7.234, de 19 de julho de 2010. Dispõe sobre o Programa Nacional de Assistência Estudantil - PNAES. Disponível em: < http://www.planalto.gov.br/ccivil 03/ ato2007-2010/2010/decreto/d7234.htm > . Acesso em: 05 set. 2020 .

Instituto Brasileiro de Geografia e Estatística, 2017. Cidades. Disponível em:

<https://cidades.ibge.gov.br/brasil/sp/capivari/panorama>. Acesso em: 05 set. 2020.

LEI No 11.892, de 29 de dezembro de 2008. Institui a Rede Federal de Educação Profissional, Científica e Tecnológica, cria os Institutos Federais de Educação, Ciência e Tecnologia, e dá outras providências. Disponível em:

$<$ http://www.planalto.gov.br/ccivil 03/ ato2007-2010/2008/lei/111892.htm>. Acesso em: 05 set. 2020.

LEI N $\mathbf{N}^{\mathbf{0}}$ 12.711, de 29 de agosto de 2012. Dispõe sobre o ingresso nas universidades federais e nas instituições federais de ensino técnico de nível médio e dá outras providências. Disponível em: < http://www.planalto.gov.br/ccivil 03/ ato20112014/2012/lei/112711.htm>. Acesso em: 03 set. 2020.

LEI No 9.394, de 20 de dezembro de 1996. Estabelece as diretrizes e bases da educação nacional. Disponível em: < http://www.planalto.gov.br/ccivil 03/leis/19394.htm>. Acesso em: 04 set.2020

PORTARIA NORMATIVA No $\mathbf{N}^{\mathbf{3 9}}$, de 12 de dezembro de 2007- Institui o Programa Nacional de Assistência Estudantil - PNAES. Disponível em:

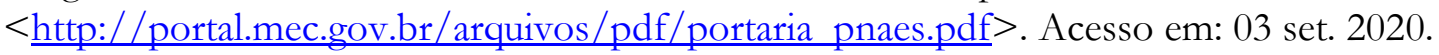

RESOLUÇÃO N.01/2019, de 12 de março de 2019. Aprova o Plano de Desenvolvimento Institucional (PDI) 2019-2023. Disponível em: $<$ https://ifsp.edu.br/component/content/article/91-assuntos/desenvolvimentoinstitucional/desenv-institucional/176-pdi>. Acesso em: 02 out. 2020. 
RESOLUÇÃO N.42/2015, de 02 de junho de 2015. Altera a Normatização dos Auxílios da Política de Assistência Estudantil (PAE) do Instituto Federal de Educação, Ciência e Tecnologia de São Paulo.

CURY, C.R.J. A educação escolar, a exclusão e seus destinatários. Educação em Revista, Belo Horizonte, nº48, p.205-222, dez. 2008. Disponível em:

$<$ https://www.scielo.br/scielo.php?script $=$ sci arttext\&pid=S0102-46982008000200010 $>$. Acesso em: 17 ago. 2020

DUARTE, Amanda Machado dos Santos. A cartografia da permanência estudantil nos cursos de nível médio da Rede Federal de Educação. 2019. 230 f. Tese (Doutorado em Serviço Social) - Programa de Estudos Pós-Graduados em Serviço Social, Pontifícia Universidade Católica de São Paulo, São Paulo, 2019.

EZCURRA, Ana María. Masificación y enseñanza superior: una inclusión excluyente. Algunas hipótesis y conceptos clave. In: FERNÁNDEZ LAMARRA, Norberto; PAULA, Maria de Fátima Costa de (Orgs.). La democratización de la educación superior en América Latina Límites y posibilidades. Saenz Peña: EDUNTREF, 2011. p. 60-72

MATTOS, Luiz Alves de. Primórdios da educação no Brasil: o período heroico (1549 a 1570). Rio de Janeiro: Aurora, 1958.

NEVES, Paulo Sérgio da Costa; LIMA, Marcus Eugênio Oliveira. Percepções de justiça social e atitudes de Estudantes pré-vestibulandos e universitários sobre as cotas para negros e pardos nas universidades públicas. In: MACON, Frank; SUBRINHO, Josué Modesto dos Passos (Org.). Ações afirmativas e políticas inclusivas no ensino e público superior: a experiência da Universidade Federal de Sergipe - São Cristóvão: Editora UFS, 2010. 180p. ISBN: 987-85-7822-131-7

PACHECO, Eliezer Moreira. Os institutos federais: uma revolução na educação profissional e tecnológica. Natal: IFRN, 2010. 28 p. ISBN 978-85-89571-68-5

PILETTTI, Nelson. História da Educação no Brasil. São Paulo: Ática, 2010.

PIOVESAN, Flavia. Ações afirmativas da perspectiva dos direitos humanos. Cadernos de Pesquisa, v. 35, n. 124, p. 43-55, jan./abr. 2005

RIBEIRO, Maria Luisa S. História da educação brasileira: a organização escolar. São Paulo: Moraes, 1986. 